\title{
The Study on Learning Experience of Nursing Students' Action-Learning-based Postpartum Hemorrhage Management
}

\author{
Sun-Hee Bae1), Sang-Mi Noh2) Young-Sun Park3)
}

\begin{abstract}
The purpose of this phenomenological study was to provide fundamental data to learning method field by investigating the meaning such as thoughts and feeling of experience of 18 th grade nursing students who participated in the action-learning-based experience of postpartum hemorrhage management simulation. The data were collected from Oct. 1, to Nov. 1, 2018 and the date collected from the focus group interview were analyzed using Colaizzi's analytical procedure. One hundred and seventeen constructs were extracted from the original data, based on which, 40 themes and 15 theme clusters were derived. Five categories were determined through systematic conceptualization: "broad and deep achievement of learning", "Recognition of importance of teamwork", "accumulation of experience in virtual clinical practice guiding direction", "improvement in skills of coping clinical practice", and "burden on lesson". The results showed that the action-learning-based learning of postpartum hemorrhage management simulation increase the satisfaction with the learning achievement and the coping skill and performance of nursing students. It is recommended to apply more effective action learning method in the health care field as well as more various curriculums.
\end{abstract}

Keywords: Nursing Students, Action Learning, Simulation, Learning, Qualitative Study

\section{Introduction}

The convergence of ICT and healthcare technology fueled by the 4th industrial revolution, in the recent healthcare environment, has led to changes in the healthcare paradigm[1] and increase in demand for premium nursing care and for nurses with high quality of nursing skills. The nurses required by the modern society are nursing professionals who can select and

Received(April 29, 2019), Review Result(1st: May 22, 2019, 2nd: July 19, 2019), Accepted(September 10, 2019)

1)(Assistant Professor) 11138 Dept. Nursing, Kyungbok University, 154 Sinpyeong-ro Sinbuk-myeon, Pocheon-si, Gyeonggi-do, Korea

email: shbae@kbu.ac.kr

2)(Assistant Professor) 11138 Dept. Nursing, Kyungbok University, 154 Sinpyeong-ro Sinbuk-myeon, Pocheon-si, Gyeonggi-do, Korea

email: smnoh@kbu.ac.kr

3)(Associate Professor, Corresponding Author) 11138 Dept. Nursing, Kyungbok University, 154 Sinpyeong-ro Sinbuk-myeon, Pocheon-si, Gyeonggi-do, Korea

email: yspark@kbu.ac.kr 
implement effective problem-solving methods through integrated and critical thinking based on the knowledge of the nursing rather than a knowledgeable practitioners[2]. The current teaching method occupying largest part in university is the traditional lecture class, which has many limitations in education paradigm aiming at change of attitude and behavior, promotion of various thinking, and formation of values[3]. The additional disadvantages of the traditional lecture class are that as the number of students increases, the personal consideration between the professor and the student decreases and that professors are tend to teach the students to achieve just the educational goals and to control them using the hierarchical force[4]. The universities, in order to overcome these problems, need competency-based learning that develops the ability to perform problem-solving and cooperative learning, and ability for the learners to perform skillfully their tasks and roles in the academic, career, and life domains[5]. The nursing students, in particular, as prospective nurses, are required to have the capacity to solve problems that may arise in various nursing fields through creative thinking and problem solving[6]. Action Learning, a learning method that solves a task or a project with a fellow learner in a small team, allows learners to acquires knowledge in problem-solving and learn the contents of task and course of solving problem through the course of using the question, feedback, and learning[7]. Another advantage of this learning method is the improvement of error correction, academic achievement and clinical performance in a safe environment and development of critical thinking, confidence, satisfaction, and preliminary confirmation of the outcome of the intervention chosen by him/herself as well as experience in cases that are difficult to perform in clinical practice[8]. The postpartum hemorrhage management which is difficult to be observe in the clinical nursing setting was addressed, in this study, by applying the learning elements of action learning into the simulation class, after which, the focus group interview was performed to understand more deeply the meaning of the nursing students' action-learning-based experience of postpartum hemorrhage management simulation. The purpose of this study was to provide basic data on the learning method by understanding and describing cleary the experiences for the nursing students of action-learning-based postpartum bleeding simulations.

\section{Method}

\subsection{Design}

This phenomenological study used focus group interview to investigate the essence of the 
nursing students' action-learning-based experience of postpartum hemorrhage management simulation. The essence in this study means a key meaning understood in a same way by those who shard an experienced of the phenomenon.

\subsection{Subjects}

The subjects were fourth grade students in nursing department from $\mathrm{K}$ University who had action-learning-based experience of postpartum hemorrhage management simulation for the improvement of their competency-based performance and satisfied following criteria:

1) Being able to communicate with researchers and clear and consistent in thinking and judgement

2) Being able to understand the purpose of this study and to fill the consent form on his/her own.

\subsection{Data}

The data were collected from 1st Oct. to 1st Nov., 2018. The focus group interview was conducted in 18 students (female $\mathrm{n}=14$ male $\mathrm{n}=4$ ) who participated in the action-learning-based experience of postpartum hemorrhage management simulation the improvement of their competency-based performance and were enrolled in 4 th grade of the $\mathrm{K}$ university nursing department. They were divided into two teams ( $n=7$ and 11, respectively) for which interviews were carried out in a simulation lecture room of $\mathrm{K}$ university. The time required for interview was 2-2.5 hours. The interviews were audio-recorded under the consent of the subjects, and the actions, words, facial expression, experiences, and feelings of them during interview were also recorded and analyzed. Interviews and analyzes were conducted in a cyclical process in a way that data were transcribed after each interview and, based on which, the contents of the next interview were constructed. The main questions of the interview were "What was your experience in this class?", "How did you feel when you received continuous feedback from professor?", and "What was the meaning of self-reflection for you?"

\subsection{Data Anaysis}

This study adopted the analytical procedure of Colaizzi[9] to find clear meaning in the contents 
described by the participants and to make them to state the essence of the phenomenon accurately. The analysis process were as follows:

Step 1: In order to understand the feelings of the experience of action-learning-based experience of postpartum hemorrhage management simulation, the subject's recorded states were transcribed rightly while listening to them several times.

Step 2: All the manuscripts were read repeatedly to extract the feelings contained in the material. The meaningful sentences or phrases directly expressing the research phenomenon were obtained from the subjects' statements.

Step 3: The duplicated expressions among the meaningful statements were excluded and redescribed in general forms.

Step 4: The meanings of meaningful phrases or phrases in the researcher's language, taking care not to deviate from the meaning of the original statement.

Step 5: The theme was extracted from the structure of the derived meaning, and the subjects' statements related to themes were clustered and further categorized.

Step 6: After integrating the analyzed contents into one descriptive method and were described as a statement about the essential structure of the research phenomenon.

Step 7: The final descriptions were read by subjects as well as researchers to check they match the experience of the participants and thus secure the validity.

The properties and contents derived through above courses were subjected to advice from two professors in the $\mathrm{K}$ University to ensure validity and reliability.

\subsection{Ethical Consideration}

The researchers explains to the subjects the purpose and meaning of study and importance of cooperativeness in conducting data collection and analysis and allows them to voluntarily decide whether to participate in the research. They were noted that each subjects were represented as anonymous in the course of research, that the materials were not used only for other purposes other than research, that the audio-recorded material would be discard immediately after completion of study, and that they had a right to refuse participation in the study at any time in the course of study. Many efforts, in addition, were exerted to protect the privacy of subjects. The subjects were given with detailed written consent describing the purpose and process of study, the rights of subjects, and the contact details of the researcher, 
and signed by the authors. After the completion of the study, minor gifts were provided to subjects.

\subsection{Rigor and Reliability}

This study, to improve rigor and reliability of study, followed truth value, neutrality, consistency, and applicability presented by Guba and Lincoln[9]. The results described and analyzed by researchers were communicated to some subjects through e-mail or direct interview to increase the truth value. The neutrality were acquired by pre-understanding of researchers on study and excluding their prejudice and judgement. The consistency were ensured by subjecting the analysis process and results to verification of a nursing professor unrelated to this study and with extensive experience in qualitative research. This study intended to provide fundamental data for development of programs helpful in students' positive adaptation by investigating the essence of action-learning-based experience of postpartum hemorrhage management simulation, suggesting an effort to increase applicability.

\subsection{Readiness of Researcherers}

One of the authors is a nursing professor lecturing at a university. The author completed the subjects related to phenomenological research method in graduate school and, through oral and poster presentations on qualitative research method, has improved competency to conduct qualitative research. The author, in particular, received master's degree in phenomenology and doctor's degree in ethnography. The author ensured validity and reliability of this qualitative study by improving the proficiency of the research under the guidance of the qualitative research experts and by demonstrating the function and ability of researcher as a research tool.

\section{Results}

\subsection{Meaning of Nursing Students' Action-learning-based Experience of Postpartum Hemorrhage Management Simulation}

One hundred and seventeen constructs were extracted from the original data, based on which, 40 themes and 15 theme clusters were derived. Five categories were determined through systematic conceptualization: "broad and deep achievement of learning", "Recognition of 
importance of teamwork", "accumulation of experience in virtual clinical practice guiding direction", "improvement in skills of coping clinical practice", and "burden on lesson".

[Table 1] Meaning of Nursing Students' Action-learning-based Experience of Postpartum Hemorrhage Management Simulation

\begin{tabular}{|c|c|c|}
\hline Category & Theme Cluster & Theme \\
\hline \multirow{11}{*}{$\begin{array}{l}\text { Broad and } \\
\text { Deep } \\
\text { Achievement of } \\
\text { Learning }\end{array}$} & \multirow{3}{*}{$\begin{array}{l}\text { Satisfaction with } \\
\text { Continuous Learning } \\
\text { Through Self-Reflection }\end{array}$} & Change through self-reflection. \\
\hline & & Self-reflection used as a learning material. \\
\hline & & Opportunity in self-reflection to correct wrong ones. \\
\hline & \multirow{4}{*}{$\begin{array}{l}\text { Satisfaction with Deep } \\
\text { Learning }\end{array}$} & Deeper contents of learning through feedback. \\
\hline & & Satisfaction with detail explanation. \\
\hline & & Deeper contents of learning not limited to textbook \\
\hline & & Varisous contents not limited to theories. \\
\hline & \multirow{4}{*}{$\begin{array}{l}\text { Satisfaction with Learning } \\
\text { Through Answering }\end{array}$} & 3why technique to emphasize real situation. \\
\hline & & Voluntary answering by 3 why technique \\
\hline & & $\begin{array}{l}\text { Feeling of achievement from the self-directed } \\
\text { learning }\end{array}$ \\
\hline & & Induction of direct participation by 3 why technique \\
\hline \multirow{4}{*}{$\begin{array}{l}\text { Recognition of } \\
\text { Importance of } \\
\text { Teamwork }\end{array}$} & \multirow{2}{*}{$\begin{array}{l}\text { Responsibility for } \\
\text { Emphasized Team Learning }\end{array}$} & Responsibility fo team learning. \\
\hline & & Team members free-riding. \\
\hline & \multirow{2}{*}{$\begin{array}{l}\text { Recognition of Importance } \\
\text { of Teamwork }\end{array}$} & Recognition of importance of cooperation. \\
\hline & & Recognition of importance of communication \\
\hline \multirow{10}{*}{$\begin{array}{c}\text { Accumulation } \\
\text { of Experience } \\
\text { in Virtual } \\
\text { Clinical } \\
\text { Practice } \\
\text { Guiding } \\
\text { Direction }\end{array}$} & \multirow{3}{*}{$\begin{array}{l}\text { Tense in Simulation } \\
\text { Situation }\end{array}$} & $\begin{array}{l}\text { Simulation situation where the nursing courses are } \\
\text { not reminded. }\end{array}$ \\
\hline & & Simulation situation unrelated to theory. \\
\hline & & Simulation situation inducing dull feeling. \\
\hline & \multirow{5}{*}{$\begin{array}{l}\text { Opportunity of Direct } \\
\text { Performance in Virtual } \\
\text { Situation }\end{array}$} & Opportunity to learn in as-like clinic situation. \\
\hline & & $\begin{array}{l}\text { Opportunity to learn in more detail than clinical } \\
\text { practice. }\end{array}$ \\
\hline & & Opportunity to use directly the devices. \\
\hline & & Only opportunity to perform directly. \\
\hline & & Opportunity to play the role of charge nurse. \\
\hline & \multirow{2}{*}{$\begin{array}{l}\text { Detail Explanation to } \\
\text { Guide Direction }\end{array}$} & Guide to decrease the burden on lack of knowledge. \\
\hline & & Video clips cases to introduce the situation. \\
\hline \multirow{4}{*}{$\begin{array}{l}\text { Improvement } \\
\text { in Skills of } \\
\text { Coping Clinical } \\
\text { Practice }\end{array}$} & \multirow{3}{*}{$\begin{array}{l}\text { Improvement in Insight } \\
\text { into Situation }\end{array}$} & Action plan confirmed in a glance. \\
\hline & & Expanded insight by discussion with team members. \\
\hline & & Insight learning to link those learnt just theoretically. \\
\hline & Improvement in Coping & Shameful of seeing themselves running about in \\
\hline
\end{tabular}



http://dx.doi.org/10.21742/apjcri.2019.09.12

\begin{tabular}{|c|c|c|}
\hline & \multirow[b]{2}{*}{ Skill through Awakening } & confusion, during debriefing session. \\
\hline & & $\begin{array}{l}\text { Comparison between teams through debriefing } \\
\text { session. }\end{array}$ \\
\hline & \multirow{2}{*}{$\begin{array}{c}\text { Continuity in Learned } \\
\text { Contents }\end{array}$} & Rich learning as much the difficulties \\
\hline & & Longer remembrance of learned contents. \\
\hline & \multirow{2}{*}{ Improved Job Capacity } & Increase in confidence for nursing work. \\
\hline & & Improve in copying ability in clinical situation. \\
\hline \multirow{6}{*}{$\begin{array}{l}\text { Burden on } \\
\text { Lesson }\end{array}$} & \multirow{2}{*}{ Burden on Simulated Role } & Difficulty in playing the role of charge nurse. \\
\hline & & Burden on the role of charge nurse. \\
\hline & \multirow{2}{*}{ Burden on Self-Reflection } & Burden on self-reflection. \\
\hline & & Self-blame on the wrongs fund in self-reflection. \\
\hline & \multirow{2}{*}{$\begin{array}{l}\text { Burden on Unprepared } \\
\text { Learning }\end{array}$} & Burden on class. \\
\hline & & Burden on action plan requiring creativity. \\
\hline
\end{tabular}

\subsection{Description of Meaning Structure of Nursing Students' Action-learning-based Experience of Postpartum Hemorrhage Management Simulation}

\subsubsection{Category I: Broad and Deep Achievement of Learning}

Theme Cluster I-1: Satisfaction with Continuous Learning through Self-Reflection

The subjects of this study were shown to be satisfied with the opportunities to utilize the contents of the study as self-reflection materials for continuous learning and to remember the contents and correct the mistakes.

"That's definitely the material. There is no learning material. However, I can use the handwriting I have made so that I can study it before class. It seems to be a kind of reference."

"When I write such a reflection $\log$, I plans what I should do at next simulation class and find what needed to be complement. That is a course of increasing my understanding."

\section{Theme Cluster I-2: Satisfaction with Deep Learning}

The subjects of this study were shown to be satisfied with the opportunity to get deeper understanding through the professor's feedback and explanation. They were also satisfied with the fact that the contents are not limited to textbooks and theories but practically used in clinics. 
"After PBL, the professor feedback made me to be surprised about the depth of the content and that really helped me a lot."

"After the simulation, when the professor explained, she asked us o think about the reasons for each step, and she explain them one by one afterwards. That is an excellent way to remember something longer."

"I learned only theories in class, but in PBL (Problem-based Learning) I learned much deeper contents that were not found even in textbooks and that I never thought of.

\section{Theme Cluster I-3: Satisfaction with Learning through Answering}

The subjects of this study were embarrassed with continuous questions about application of 3why technique, however, became participate more actively in lecture while answering and were shown to feel achievement with the self-learning.

"I wanted the professor to ask 'why?', 'why?' and 'why?', however, in a moment I became to understand the content and it helped me finally. The professor feedback included even the contents of next exam."

"The free induction of professor helped me to answer. Perhaps it is because that is more natural way to induce answering rather than a way where the point is given only to students who answer. When the professor asked, the answers came straight out."

"I did not know why the professor ask us the reason repeatedly, however, in the course of finding the answer through web or printed materials, I realized that it is a process of learning the right answer and I was satisfied with it."

\subsubsection{Category II: Recognition of Importance of Teamwork}

\section{Theme Cluster II-1: Responsibility for Emphasized Team Learning}

The subjects of this study felt the responsibility for the team learning while watching the other members free-riding on the learning organized by team works and for the participation not to harm other members.

"It is responsibility of team members to do their best. I thought that the rating of team is determined by my efforts. That made me to try more harder and find more solutions."

"There are members free-riding on the learning. The team members were five and we were assigned to determine three nursing diagnosis. We worked together, however, some members use mobile phone. Of course, it is duty of team leader to accommodate such members, however, it is fact that they are free-riding on the class. It seems to be the case also in other teams." 
Theme Cluster II-2: Recognition of Importance of Teamwork http://dx.doi.org/10.21742/apjcri.2019.09.12

The subjects of this study were shown to recognize the importance of cooperation while helping other members not skillful in copying simulated situation and of communication with others.

"When I failed in remembering the learnt contents, the team members helped me and I felt in the situation that when I am not skillful in copying situation at real clinical field, others may help me. That explains importance of cooperation. I felt much such feeling."

"Even when I participated in class with a plan in mind, there were embarrassing situations and other members helped me and directed me to next steps. The exchange of such helping was a satisfying experience."

\subsubsection{Category III: Accumulation of Experience in Virtual Clinical Practice Guiding Direction}

Theme Cluster III-1: Tense in Simulation Situation

The subjects of this study were shown, in the process of implementing nursing in the simulation room, to be nervous and did not even try to incorporate the planned nursing process into the simulation situation. They were found to be feeling dull tension in the simulation situation.

"I could not remember anything. I keep thinking about it, however I do not remember about it. And it was harder for me to keep the pace of steps while running throughout the class."

"The patient said his legs were numbed. Even though we applied mask, he complained the numbness continuously. In fact, it was an examination. After it was over, the professor said that we had mistakenly applied the mask. I realized at the time, but I did not think of anything in the real situation."

\section{Theme Cluster III-2: Opportunity of Direct Performance in Virtual Situation}

The subjects of this study were shown to be satisfied with the opportunity to experience as-like clinic situation and to use the devices only found in textbook. They also shown to give significant meaning to the experience of limited obstetrics and gynecology practice and the opportunity of plying the role of charge nurse.

"This is only class that complement and overcome the lack of students' experience that the professors often said of."

"There were no practice class to experience the real clinic situation. This class helped much in complementing such lacks."

"In fact, considering that male students are not allowed to enter such units as obstetrics and 
gynecology ones even during the field practice, this was an excellent opportunity to experience such situation."

"I was satisfied with the opportunity to feel the clinical situations and to play the role of charge nurse and notify them even though I have no opportunity of acting and that is much far from my current position."

\section{Theme Cluster III-3: Detail Explanation to guide Direction}

The subjects of this study were shown to be satisfied with detail explanation by professors to guide and determine direction. The prepared and offered video clips explaining cases were also helpful in approaching more easily.

"In the fourth stage of labor, the nurses have to observe the degree of uterine contraction and other variables such as interval and period of the contraction. The professor gave us the necessary frame and guide. That included what the Apgar score and how it is calculated."

"The efforts to guide us were most impressive to me. When I am in still without doing anything, the professor guide me by asking what I should do. Such guidance was very helpful."

"It was more comfortable in preparing for the next time when I thought about what to do next due to the offered video clips, rather than when I entered without any preparation."

\subsubsection{Category IV: Improvement in Skills of Coping Clinical Practice}

Theme Cluster IV-1: Improvement in Insight into Situation

The subjects of this study experienced a learning where that learning is reviewed at a glance through the action plan and developed an insight to expand their knowledge to include what they did not know. These developed students' insight to link theories.

"I was helpful for me to be able to see at a glance conveniently."

"Unlike when I did them alone, I learned much more from the priorities set by other members. This expanded the scope of my thoughts. For example, a diagnosis I could not think of was taken into account through the opinion of a team member."

"In the past, I have learned theoretically each disease just individually, but in this simulation, it seems easier to organize them because I have learned all these diseases together linking them."

\section{Theme Cluster IV-2: Improvement in Coping Skill through Awakening}

Despite that the subjects of this study, during the debriefing session, were ashamed of seeing 
video clips of their performance as they were wrong and running about in confusion, they thought about what to do next. And by comparing their team with other teams, they had opportunity to compare strengths of theirs and others' and developed the coping skill through awakening.

"I was so ashamed of watching video cilps of my team with other classmates. I thought that the performance our team was worst."

"My appearance was like an idiot. I did not know what to do and was look like to blow my mind. I was staring at the other team member and not knowing what to do. I was so embarrassed."

"I came to know that I made bullshit. When we saw the performance of the other teams, we found something that our team missed, and then we learned a lot by thinking that we should not repeat the same mistakes."

\section{Theme Cluster IV-3: Continuity in Learned Contents}

The subjects of this study, though it was hard for them, learned many things through the class and confirmed that the contents are remembered longer when they did it directly, think the reason, and organize them verbally.

"It was hard, but there were something to learn as much. The class schedule was too tight and we had almost no rest time but, even after just one semester, I felt I had learned very much."

"We performed the tasks put on the blackboard directing what our team should do and it helped us a lot. It made me to review what I learned before, which were useful in remembering them."

"After PBL, we had a time to question and answer. That was unfamiliar with me but most interesting to me. It was in fact helpful in remembering the contents longer by organizing them verbally."

\section{Theme Cluster IV-4: Improved Job Capacity}

The subjects of this study were shown to develop the confidence in the nursing work through the direct performance of the contents and have improved their ability to cope rapidly in clinical practice.

"I think the contents what I remembered through this class will be helpful when I encounter the same situation in clinical situation by increasing my confidence."

"I think this class gave me the confidence that I could become a much more capable, 
brilliant, and confident nurse."

\subsubsection{Category V: Burden on Lesson}

Theme Cluster V-1: Burden on Simulated Role

The subjects of this study were shown to feel difficulties in and have burden on the role of charge nurse most seriously.

"It was too difficult. I did not know even what to notify. When you do notify, you should not stutter. After introducing me as the charge nurse of a patient in a ward, I should tell to change charge doctor, receive the prescription orally, and finally check them one more time. Those things were too difficult. At first I still can not perform acting...."

"If you play charge nurse, it's hard to keep the notify all the time, so that seems to be the case by case. No matter how we practice in team, we do not think we're going to be assigned as a charge nurse. That made me to feel more difficult when I was really assigned as the charge nurse."

\section{Theme Cluster V-2: Burden on Self-Reflection}

The subjects of this study were shown to be burdened with the need to write a lot of contents on the reflection diaries and were embarrassed with such mistakes.

"It was so hard for me to write what I felt."

"Although I have a lot to reflect on, and have learned so much, there is a limit to the amount of contents that I can fill it, I think it was hard for me to fill one page thoroughly."

"In the process of reflection, my mistake seemed so much that I had a sigh."

Theme Cluster V-3: Burden on unprepared Learning

The subjects of this study were shown to be burdened with the need for much preparation before class and for developing an action plan that required them of creativity in class.

"At first I was burdened. It was hard for me to prepare because I had to prepare a lot of things and remember that I did not even think of ${ }^{\prime \prime}$

\section{Discussion}

The subjects of this study recorded the course of self-reflection in action-learning, and based on which, experienced continuous learning and were satisfied with the opportunity to accmulate practical knowledge and experience that are needed in clinical practice. And in the application of 3way technique of action learning, they experienced the feeling of achievement where they 
gain knowledges by asking each other. Kim[4] reported that the level of participation and satisfied were reported as high when the professor was interviewed about the experience of action learning method and emphasized that strength of the action learning that the agency of learning is not the professor but students. The subjects of this study were shown to participate more vigorously not to harm other members while recognizing the importance of teamwork and to become to understand the importance of cooperation while exchanging helps in the cases of failure in copying the simulated simulations. In a virtual clinical situation where it is vague and unclear what to do, students have accumulated clinical experience through action-learning-based motivation for study, which consists of a video clips of the clinical situation and a detailed description of the professor. The action learning is very effective in developing individual competence and ability such as self-management, problem-solving, and interpersonal ones, and has a positive effect of enhancing competence such as communication and motivation[10]. Considering these findings, it is suggested that this is an effective strategy to improve the competence of nursing college students, whose ability to communicate with patients, care-givers, and other medical specialists are emphasized and where problem solving ability is important. It was shown that the nursing students gave significant meanings to the action-learning-based experience of postpartum hemorrhage management simulation, in that this provides an opportunity to experience the real obstetrics and gynecology practice in the form of simulated situation and to play the role of charge nurse, consistent with the results of Lee[11] reported that the simulation in the nursing field increased the confidence in appropriate intervention. The results of this study also showed that the competency-based performances were improved in the course of implementing action learning by discussion with other members, reflecting on the reasons, and comparing of their and other team's performance, and the resultant awakening. Although the burden on the much preparation before class and the creativity required in devising the action plan in class were observed, this is considered to have a positive effect on improving nursing students' ability of self-directed learning.

The experience of action-learning revealed in this study demonstrated the realization of self-directed learning where the students are the agency in learning, suggesting the need to increase the application of action-learning method escaping from the traditional face-to-face instruction in the nursing field. The development of nursing curriculum that apply the action learning method is also recommended. 


\section{Conclusion}

The purpose of this study was to provide basic data on the learning method by understanding and describing cleary the experiences for the nursing students of action-learning-based postpartum bleeding simulations. The subjects of this study, through the action-learning-based experience of postpartum hemorrhage management simulation, felt the feeling of achievement for the broad and deep learning and recognized the importance of teamwork. Although they had opportunity to experience the clinical practice under the direction of skillful professor, they also had some burden on the self-reflection. Given that the competency-based performance of nursing students are improved through these action learning method, it is recommend to increase the researches and application of this learning method in nursing field.

\section{References}

[1] S. J. Kim, Y. S. Kim, J. H. Kim, J. H. Lee and K. E. Chang, A study on the Development of Convergence Education Program for Workers in Health and Medical Industry in Preparation for the Forth Industrial Revolution, Journal of the Korea Convergence Society, (2018), Vol.9, No.5, pp.43-52, DOI: 10.15207/JKCS.2018.9.5.043

[2] Y. I. Park, J. A. Kim, J. K. Ko, M. S. chung, K. S. Bang, M. A. Choe, M. S. Yoo and H. Y. Jang, An Identification Study on Core Nursing Competency, The Journal of Korean Academic Society of Nursing Education, (2013), Vol.19 No.4 pp.663-674, DOI: 10.5977/jkasne.2013.09.4.663

[3] Y. S. Kim and J. Y. Kim, The effect of the Cultural Competence in Multicultural Nursing Education by Action Learning, Journal of the Korea Academia-Industrial cooperation Society, (2014), Vol.15, No.11, pp.6527-6535, DOI: 10.5762/KAIS.2014.15.11.6527

[4] M. O. Kim, A. Y. Lee and H. A. Nam, Effects on Nursing Students' Learning Flow, Critical Judgement, and Problem Solving Ability in Simulation Training: focused on Obstetrical Nursing Case, The Journal of Learner-Centered Curriculum and Instruction, (2017), Vol.17, No.24, pp.521-534, DOI: 10.22251/jlcci.2017.17.24.521

[5] Y. C. Kim and E. C. Lee, Effects of Action Learning Approach on Learning Motivation and Problem-solving Capacity in NCS Vocational Competency Class of Polytechnic College, Journal of the Korea Contents Association, (2016), Vol.16, No.11, pp.83-52, DOI: 10.5392/JKCA.2016.16.11.038

[6] K. H. Chung, Application of Action Learning Teaching-Learning Method to Improve Creativity and Problem Solving Capability, JRIS-The Journal of the Research and Information, (2010), Vol.10, pp.1-12.

[7] H. C. Bong and W. Y. Um, Action Learning, Hakjisa, (2014)

[8] E. G. Guba and Y. S. Lincoln, Fourth generation evaluation, Sage Publications, (1989) 
[9] P. F. Colaizzi, Psychological Research as the Phenomenologist Views It, Existential-phenomenological alternatives for psychology, Oxford University Press, (1978)

[10] K. W. Chang, E. H. Koh and S. I. Ko, Analysis of the Research Trend of Action Learning in School, The Korean Journal of Educational Methodology Studies, (2015), Vol.27, No.3, pp.429-455, DOI: 10.17927/tkjems.2015.27.3.429

[11] W. S. Lee and M. O. Kim, Effects and Adequacy of High-Fedelity Simulation-Based Training for Obstetrical Nursing, Journal of Korean Academy of Nursing, (2011), Vol.41, No.4, pp.433-443, UCI: G704-000229.2011.41.4.010 